\title{
Effectiveness of Saturated Coral Aggregate and Shrinkage Reducing Admixture on the Autogenous Shrinkage of Ultrahigh Performance Concrete
}

\author{
Jinming Liu, Zhongwen Ou, Jinchuan Mo, Yuzhuo Chen, Tong Guo, and Wei Deng \\ Department of Chemical and Material Engineering, Logistical Engineering University, Chongqing, China \\ Correspondence should be addressed to Jinming Liu; xiaoxiong1025@yeah.net
}

Received 22 March 2017; Accepted 7 June 2017; Published 25 July 2017

Academic Editor: Michele Zappalorto

Copyright (c) 2017 Jinming Liu et al. This is an open access article distributed under the Creative Commons Attribution License, which permits unrestricted use, distribution, and reproduction in any medium, provided the original work is properly cited.

\begin{abstract}
The use of saturated coral aggregate (SCA) as practical replacement of quartz sand has been shown to effectively mitigate the autogenous shrinkage in ultrahigh performance concrete (UHPC). The autogenous deformation, the compressive strength, the flexural strength, and the hydration property development of paste with different shrinkage means were tested. Three different methods were evaluated to mitigate the autogenous shrinkage: SCA, shrinkage reducing admixture (SRA), and the mixture of SCA and SRA (SRA-SCA). It was found that SCA and SRA have all the effective ways to reduce the shrinkage deformation, and SRA-SCA was the most effective in mitigating the shrinkage. The autogenous shrinkage of UHPC was restrained, when the SCA dosage was $44 \%$, the SRA dosage was $0.8 \%$, the SCA content was $26 \%$, the SRA dosage was $2.4 \%$, the SCA content was $18 \%$, the SRA content was $2.4 \%$, or the SCA dosage was $26 \%$. The mechanical properties were deteriorated by the addition of SCA, while the compressive strength was still higher than $90 \mathrm{MPa}$ at 28 days even though the replacement ratio of SCA was up to 50\%. Furthermore, internal curing by means of SCA was proved to be a successful way to mitigate autogenous shrinkage, after the tests.
\end{abstract}

\section{Introduction}

Currently, the application of UHPC has been developed in more and more engineering, because of high compressive strength (over $100 \mathrm{MPa}$ ), high tensile strength (over $8 \mathrm{MPa}$ ), high ductility, and high density. And UHPC overcomes the normal concrete drawback; the increase of strength is accompanied by higher brittleness $[1,2]$. These outstanding properties are attributed to the high binder content, the high ultrafine powder content, and the low water to binder ratio (W/B). Due to the low W/B (usually lower than 0.2 ) and high silica components content, the hydration heat of UHPC is high, and the internal relative humidity decreased quickly. However, these hydration reactions caused the high earlyage autogenous shrinkage and shrinkage cracking. And the shrinkage leaded to more and more cracking; this cracking became wide with the time increasing. Many liquids, gases, and ions, which are harmful to the concrete cementitious structure, will diffuse into the internal concrete through this cracking. Thus, the durability will get worse and worse, and the service life will shorten strongly [3].
It is very important and essential to restrain the autogenous shrinkage in UHPC. There are many methods to reduce the autogenous shrinkage, use of shrinkage reducing admixtures, and internal curing that have been introduced to mitigate the autogenous shrinkage in UHPC.

One method to decrease the effects of shrinkage includes the addition of shrinkage reducing admixtures. SRA has been observed to be useful in mitigating the autogenous shrinkage. The use of SRA to reduce the shrinkage has been investigated by Yoo et al. $[4,5]$, and their studies were focused on investigating the effect of SRA on free and restrained autogenous shrinkage behaviors of UHPC. Güneyisi et al. [6] summarized their researches and found that SRA effectively decreases the magnitude of capillary stresses and shrinkage strains through reducing the surface tension of capillary solution. Some researches indicated that the autogenous shrinkage of UHPC was mitigated by the addition of SRA, and the reduction of the shrinkage of UHPC with SRA could be over $50 \%$ compared to that of the control UHPC. There are some studies indicating these beneficial effects on the 
TABLE 1: Chemical composition of experiment materials\%.

\begin{tabular}{lcccccccc}
\hline & $\mathrm{CaO}$ & $\mathrm{SiO}_{2}$ & $\mathrm{Al}_{2} \mathrm{O}_{3}$ & $\mathrm{Fe}_{2} \mathrm{O}_{3}$ & $\mathrm{MgO}$ & $\mathrm{Na}_{2} \mathrm{O}$ & $\mathrm{SO}_{3}$ & $\mathrm{Loss}$ \\
\hline Cement & 64.13 & 21.43 & 2.24 & 3.78 & 2.07 & 0.78 & 2.25 & \\
$\mathrm{SF}$ & 0.52 & 94.51 & 0.61 & 0.22 & & & & \\
\hline
\end{tabular}

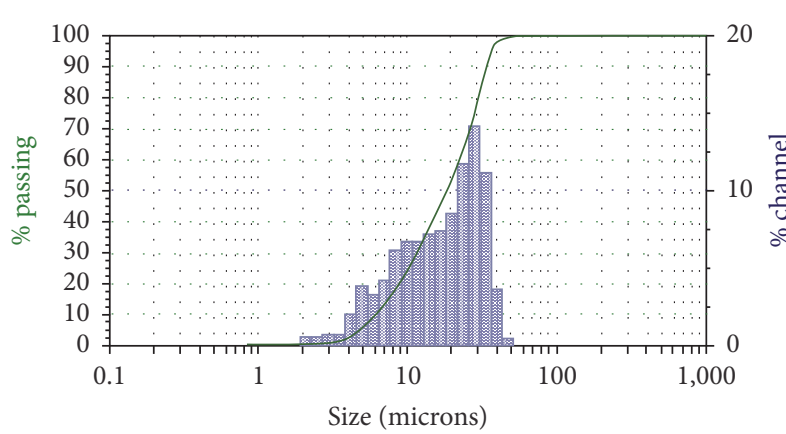

(a) Cement

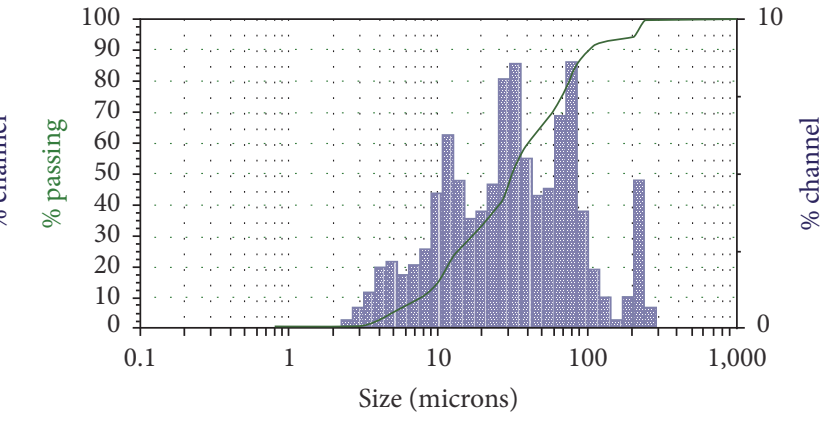

(b) Silica fume agglomerations

Figure 1: Particle size distribution of powder materials.

autogenous shrinkage of UHPC with different SRA, and the autogenous shrinkage was restrained by the use of SRA. Some researchers analyzed the impact of adding methods (mixing, coating, and immersing), dosage, and species of SRA on the shrinkage of cement paste $[7,8]$. The reducing mechanism has been investigated by Deboodt et al. [9], and their studies were focused on investigating the effect of SRA on the surface tension of pore solution and the evaporation rate of pore solution. The autogenous shrinkage was reduced by the use of SRA, which, through decreasing the pore size of cement paste, reduces the evaporation rate of pore solution.

Another shrinkage mitigation method is the use of internal curing. The internal curing [10] could reduce and even restrain the autogenous shrinkage of cement paste. It has been demonstrated that some materials can be used for concrete internal curing from the previous literature, like superabsorbent polymer (SAP) [11], bentonite clay [12], shale pottery [13], cellulose fiber [14], porous rice husk ash [15], and the lightweight aggregate (LWA) [16]. The materials used to internal curing play a role of water reservoir at hardening stage, the materials absorbed water before the paste mixing, and the water stored in the materials would be released to maintain internal relative humidity during concrete hardening, promote further hydration, and reduce the autogenous shrinkage. The SAP and LWA were usually used to mitigate the shrinkage of cement paste, and the effects on the shrinkage reduction were beneficial. In the research of Klemm and Sikora [17], autogenous shrinkage of concrete reduced with the dosage of SAP increasing, the greater the ratio of water adsorption of SAP, the more the shrinkage reduction. It has been observed that the autogenous shrinkage reduction of cement paste was about $65.3 \%$, compared to the control paste. The use of prewetted LWA reduced the amount of autogenous shrinkage deformation $[18,19]$; a $70 \%$ difference was observed between the sample with prewetted LWA and the control sample.
Although some researches have been carried out to investigate the influence of SRA and LWA on the autogenous shrinkage of UHPC, none of the studies have focused on the impact of using saturated coral aggregate (SCA) and the combination of SRA and SCA $[20,21]$ on the autogenous shrinkage of UHPC, while the water, in the internal prone of SCA, would be released and caused the internal curing. The autogenous shrinkage of UHPC will be reduced with the addition of SCA, from the view of the internal curing theoretical analysis. This paper attempts to investigate the impact of SCA, SRA, and the combination of SCA and SRA on the autogenous shrinkage of UHPC, and the effects on the UHPC properties with SCA, SRA, and the combination of SCA and SRA.

\section{Experimental Program}

2.1. Materials. Portland cement (PC) and silica fume (SF) were used as the cementitious component of UHPC. The chemical composition of PC (Cement II 42.5R) and SF is presented in Table 1, SF with $\mathrm{SiO}_{2}$ content more than $94 \%$ was used in this study, and the particle size distribution of these PC and SF is provided in Figure 1. Quartz sand with a mean particle diameter of $0.075-0.6 \mathrm{~mm}$ was used as aggregate, and quartz powder with a mean particle diameter of $5.47-18 \mu \mathrm{m}$ was added as microfiller. The steel fibers were used in UHPC to increase the tensile strength and toughness, having the specific gravity of 7.8, the length of $40 \mathrm{~mm}$, and the diameter of $0.65 \mathrm{~mm}$. A polycarboxylate-based high-range superplasticizer (SP) was employed in UHPC to achieve the target workability; the dosage in all samples was kept at a rate $2.4 \%$ of binder mass.

The main components of coral aggregate are carbonate, and the calcium content is up to $98 \%$. Table 2 shows the main determinations of coral aggregate. There are abundant pore structures and porous microstructure in coral aggregate, 


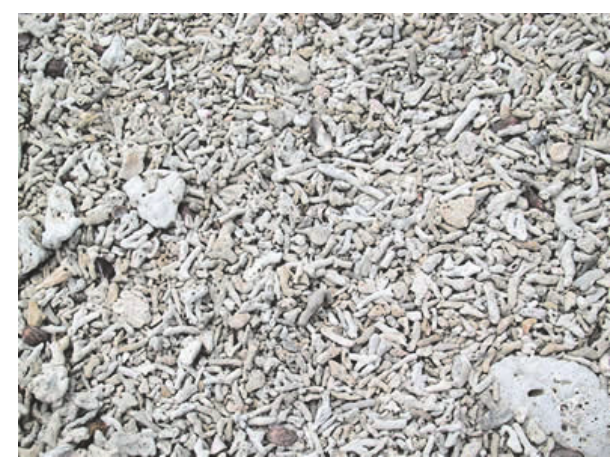

(a)

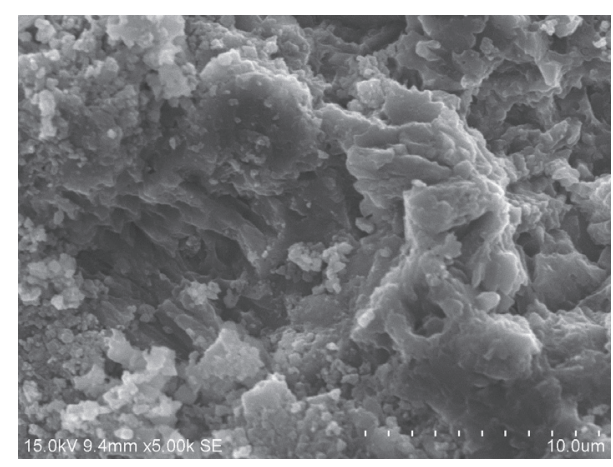

(b)

FIGURE 2: The images of coral aggregate in China.

TABLE 2: The properties testing table of coral aggregate in China.

\begin{tabular}{lcc}
\hline Detecting items & Units & Detecting results \\
\hline Moisture content & $\%$ & 0.2 \\
Organic matter & $\mathrm{g} / \mathrm{kg}$ & 2.77 \\
Available phosphorus & $\mathrm{mg} / \mathrm{kg}$ & 6.8 \\
$\mathrm{pH}$ & & 9.3 \\
Bulk density & $\mathrm{mg} / \mathrm{m}^{3}$ & 1.37 \\
Texture & & Sand \\
Available nitrogen & $\mathrm{mg} / \mathrm{kg}$ & 12.0 \\
Available potassium & $\mathrm{mg} / \mathrm{kg}$ & 7.38 \\
Carbonate & $\mathrm{g} / \mathrm{kg}$ & 987 \\
EC value & $\mathrm{mS} / \mathrm{cm}$ & 0.140 \\
Total nitrogen & $\mathrm{g} / \mathrm{kg}$ & 0.174 \\
Total phosphorus & $\mathrm{g} / \mathrm{kg}$ & 0.075 \\
Total potassium & $\mathrm{g} / \mathrm{kg}$ & 0.991 \\
Available boron & $\mathrm{mg} / \mathrm{kg}$ & 0.201 \\
Cation exchange capacity & $\mathrm{cmol} / \mathrm{kg}$ & 1.22 \\
Available copper & $\mathrm{mg} / \mathrm{kg}$ & 0.218 \\
Available zinc & $\mathrm{mg} / \mathrm{kg}$ & 0.073 \\
Available iron & $\mathrm{mg} / \mathrm{kg}$ & 0.582 \\
\hline
\end{tabular}

as shown in Figure 2. Before the experiment, the coral aggregates were sieved, and only those retaining on $2 \mathrm{~mm}$ sieve and passing $4 \mathrm{~mm}$ sieve were selected as the aggregate for this research. The saturated coral aggregates (SCA) were prepared for this study to be used in the UHPC mixes, and the water absorption of SCA is $19.2 \%$. The chloride content of coral aggregates was removed by freshwater soaking to meet the China National Standard GB 50666-2011 "Concrete Structure Engineering Construction Standard" requirements [22]. A commercially available shrinkage reducing admixture (SRA) produced in Chongqing China was used in the study.

2.2. Mix Proportions and Mixing Procedure. Table 3 shows the UHPC mixture proportions used in this research. In order to study the effect of SCA and SRA on the properties of RPC, a series of samples (with W/B from 0.2 to 0.28 ) were prepared. SCA was added at five dosage levels and the amounts of SRA were from $0.8 \%$ to $4 \%$ by mass of binder.
The mixing procedure was performed according to China National Standard GB/T 31387-2015 "Reactive Powder Concrete" [23] as follows:

(1) All dry mixing powders (PC, SF, quartz sand, quartz powder, and steel fiber) being added and mixed for $4 \mathrm{~min}$

(2) Addition $90 \%$ of the water mixture with SP and SRA and wet mixing for $4 \mathrm{~min}$

(3) SCA and the rest water mixture being added

(4) Mixing for $5 \mathrm{~min}$

\subsection{Methods}

2.3.1. Strength Test. The samples were cured according to China National Standard GB/T50081-2002 "Ordinary Concrete Mechanics Performance Test Method" [24]. After mixing, the slurry was poured into the $40 \mathrm{~mm} \times 40 \mathrm{~mm} \times 160 \mathrm{~mm}$ molds and incubated at $25^{\circ} \mathrm{C}$ for $24 \mathrm{~h}$. The specimens were maintained at $20^{\circ} \mathrm{C}$ for 27 days after the molds were removed.

The strength test of samples was performed through the computer controlled electrohydraulic testing machine. The loading rate of flexural strength test was set as $50 \pm 10 \mathrm{~N} / \mathrm{s}$. After the flexural test, the remaining six broken pieces were subjected to the compressive test. The loading rate of all specimens was set as $2.4 \pm 0.2 \mathrm{KN} / \mathrm{s}$.

2.3.2. Setting Time. For a restrained concrete element, the deformation before initial setting has negligible influence on the stress development. Therefore, the initial setting time is usually seen as the start point of autogenous shrinkage [25, 26]. ASTM C403 testing method [27] was used to measure the initial and final setting time. To eliminate the influence of water evaporation on setting time, the surface of samples needed to be covered by polyethylene sheet during the measurement.

2.3.3. Hydration Heat. The hydration heat flow of samples is measured by an eight-channel TAM Air heat conduction calorimeter. In order to minimize the influence of rising temperature caused by external mixing and handling of samples, 
TABLE 3: The mix proportion of UHPC.

\begin{tabular}{|c|c|c|c|c|c|c|c|c|c|c|}
\hline \multirow{2}{*}{ Sample } & \multicolumn{2}{|c|}{ Binder (mass fraction) } & \multirow{2}{*}{ Quartz powder ${ }^{\mathrm{a}}$} & \multirow{2}{*}{ Quartz sand $^{\mathrm{a}}$} & \multirow{2}{*}{ Coral sand $^{\mathrm{a}}$} & \multirow{2}{*}{$\mathrm{W} / \mathrm{B}^{\mathrm{b}}$} & \multirow{2}{*}{$(\mathrm{W} / \mathrm{B})_{\mathrm{e}}{ }^{\mathrm{b}}$} & \multirow{2}{*}{$\mathrm{SP}^{\mathrm{a}}$} & \multirow{2}{*}{$\mathrm{SRA}^{\mathrm{a}}$} & \multirow[t]{2}{*}{$\mathrm{ST}^{\mathrm{c}} \%$} \\
\hline & Cement & SF & & & & & & & & \\
\hline S1 & 0.8 & 0.2 & 0.34 & 0.88 & & 0.2 & & 0.024 & & 1 \\
\hline S2 & 0.8 & 0.2 & 0.34 & 0.79 & 0.09 & 0.2 & 0.02 & 0.024 & & 1 \\
\hline S3 & 0.8 & 0.2 & 0.34 & 0.70 & 0.18 & 0.2 & 0.03 & 0.024 & & 1 \\
\hline S4 & 0.8 & 0.2 & 0.34 & 0.62 & 0.26 & 0.2 & 0.05 & 0.024 & & 1 \\
\hline S5 & 0.8 & 0.2 & 0.34 & 0.53 & 0.35 & 0.2 & 0.06 & 0.024 & & 1 \\
\hline S6 & 0.8 & 0.2 & 0.34 & 0.44 & 0.44 & 0.2 & 0.08 & 0.024 & & 1 \\
\hline S7 & 0.8 & 0.2 & 0.34 & 0.88 & & 0.2 & & 0.024 & 0.008 & 1 \\
\hline S8 & 0.8 & 0.2 & 0.34 & 0.88 & & 0.2 & & 0.024 & 0.024 & 1 \\
\hline S9 & 0.8 & 0.2 & 0.34 & 0.88 & & 0.2 & & 0.024 & 0.04 & 1 \\
\hline $\mathrm{S} 10$ & 0.8 & 0.2 & 0.34 & 0.88 & & 0.22 & & 0.024 & & 1 \\
\hline S11 & 0.8 & 0.2 & 0.34 & 0.88 & & 0.23 & & 0.024 & & 1 \\
\hline $\mathrm{S} 12$ & 0.8 & 0.2 & 0.34 & 0.88 & & 0.25 & & 0.024 & & 1 \\
\hline $\mathrm{S} 13$ & 0.8 & 0.2 & 0.34 & 0.88 & & 0.26 & & 0.024 & & 1 \\
\hline S14 & 0.8 & 0.2 & 0.34 & 0.88 & & 0.28 & & 0.024 & & 1 \\
\hline S15 & 0.8 & 0.2 & 0.34 & 0.79 & 0.09 & 0.2 & 0.02 & 0.024 & 0.008 & 1 \\
\hline S16 & 0.8 & 0.2 & 0.34 & 0.70 & 0.18 & 0.2 & 0.03 & 0.024 & 0.008 & 1 \\
\hline S17 & 0.8 & 0.2 & 0.34 & 0.62 & 0.26 & 0.2 & 0.05 & 0.024 & 0.008 & 1 \\
\hline S18 & 0.8 & 0.2 & 0.34 & 0.79 & 0.09 & 0.2 & 0.02 & 0.024 & 0.024 & 1 \\
\hline S19 & 0.8 & 0.2 & 0.34 & 0.70 & 0.18 & 0.2 & 0.03 & 0.024 & 0.024 & 1 \\
\hline S20 & 0.8 & 0.2 & 0.34 & 0.62 & 0.26 & 0.2 & 0.05 & 0.024 & 0.024 & 1 \\
\hline
\end{tabular}

${ }^{\mathrm{a}}$ Fraction by binder mass. ${ }^{\mathrm{b}}$ Not including water from SP and SRA. ${ }^{\mathrm{c}}$ Volume percentage. ${ }^{\mathrm{e}}$ Water in the aggregates.

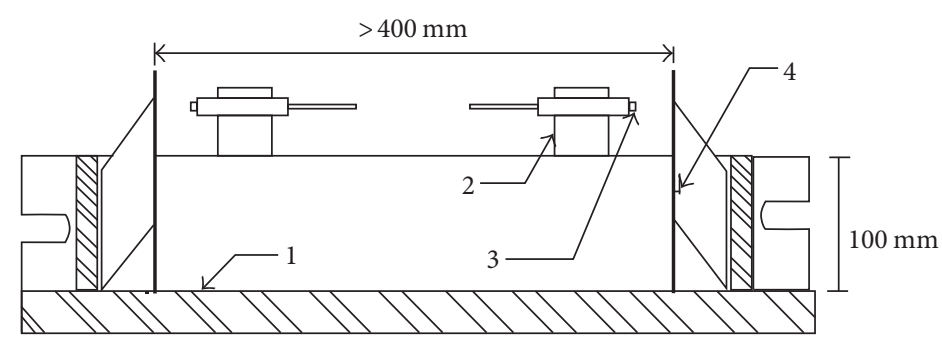

FiguRE 3: Noncontact concrete shrinkage deformation testing system. 1: steel mold; 2: sensor support; 3: displacement sensor; 4: standard target.

collecting the hydration heat data should be started $1 \mathrm{~h}$ later after mixing. The test needed to last for $72 \mathrm{~h}$, and the operating temperature was kept at $20^{\circ} \mathrm{C}$ during the whole procedure. At last, the results were normalized by gram of paste.

2.3.4. Autogenous Shrinkage Test. The linear autogenous shrinkage of UHPC is measured by using eddy-current displacement sensor (ECDS) based on the electromagnetic induction effect [25]. The schematic drawing of this apparatus is shown in Figures 3 and 4. The operation sequences are as follows:

(1) Smear the inner surfaces of steel mold $(100 \times 100 \times$ $550 \mathrm{~mm}$ ) with grease and then place Teflon sheet to eliminate the friction between the inner surfaces of mold and UHPC specimens

(2) Put two steel target seats on the proper position of the bottom surface of molds; the distance of two steel target was set as $455 \mathrm{~mm}$ in this study. Standard targets were magnetically attached to steel target seats.

(3) Cast the mixtures into molds and embed the steel target seats into RPC specimens to make sure they deform simultaneously with UHPC. Then embed the thermocouples at the center of UHPC mixtures to separate the autogenous shrinkage from the measured total deformation by monitoring the temperature change within RPC.

(4) Seal the top surface of UHPC mixture with two layers of polyethylene sheets to avoid the influence of exterior drying. After that, fasten the sensor support on the top of mold and regulate the fitting screw to make the ECDS on the proper position.

(5) Start the test. Interval of measurement data acquisition was set as one minute in this study. 


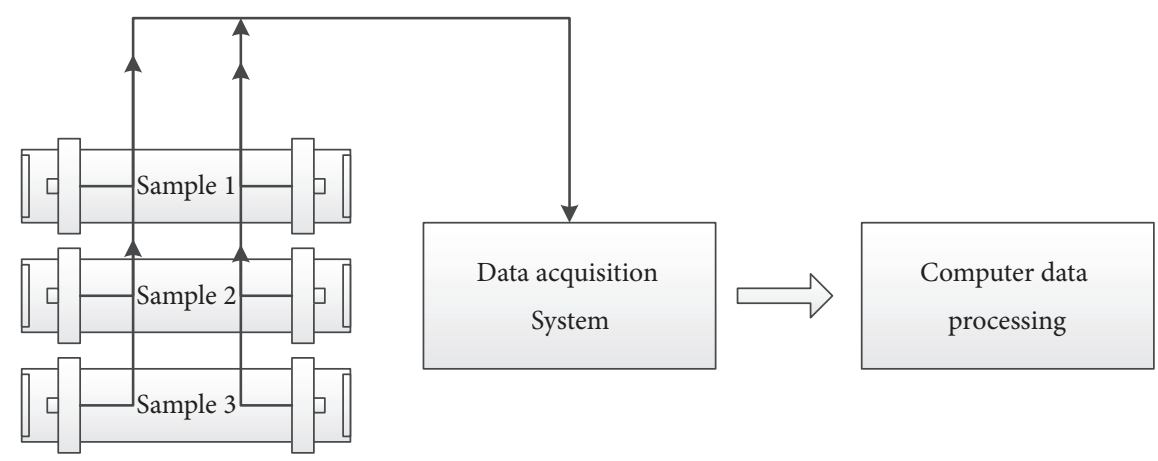

FIGURE 4: Schematic diagram of the UHPC autogenous shrinkage test.

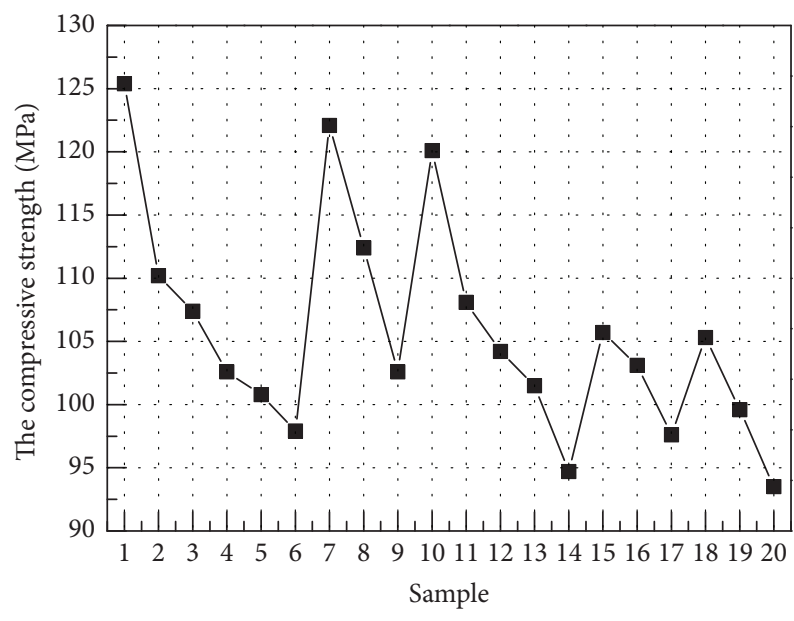

FIGURE 5: The compressive strength of specimens at 28 days.

During the whole testing period, the temperature should be kept at $20 \pm 1^{\circ} \mathrm{C}$. After the test, the measured autogenous shrinkage should be zeroed at the initial setting time determined by corresponding pure paste. The deformation results should be obtained by measuring three specimens in parallel to make sure the better estimation of autogenous shrinkage.

\section{Experimental Results and Discussion}

3.1. Mechanical Strength. The compressive strength of specimens [28] at 28 days is shown in Figure 5, and the flexural strength of specimens at 28 days is shown in Figure 6.

The compressive strength decreased with the SCA, SRA, and W/B increasing. Compared with reference S1, the compressive strength decreased $12.1 \%, 14.4 \%, 18.2 \%, 19.6 \%$, and $21.9 \%$, respectively, with increasing SCA from $9 \%$ to $44 \%$, the compressive strength decreased $2.6 \%, 10.4 \%$, and $18.2 \%$, respectively, with increasing SRA from $0.8 \%$ to $2.4 \%$, and the compressive strength decreased $4.2 \%, 13.8 \%, 16.9 \%, 19.1 \%$, and $24.5 \%$ as the $\mathrm{W} / \mathrm{B}$ increases from 0.20 to 0.28 . The superhigh strength of UHPC is obtained due to the homogeneity and extremely compacting structure. However, the homogeneity was changed as the porous SCA was added to UHPC, and the extremely compacting structure was broken with more SRA or higher W/B. The strength of specimens

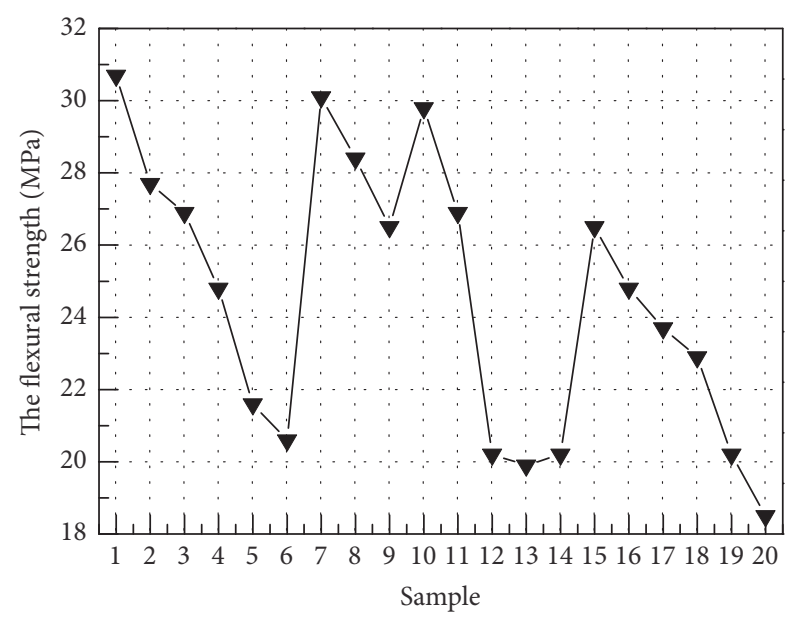

FIgURE 6: The flexural strength of specimens at 28 days.

with SCA and SRA was lower than that without SCA when the SRA content was the same. When the SRA content was $0.8 \%$, the compressive strength of samples decreased with increasing SCA compared with reference S7. The decent degree was $13.4 \%, 15.5 \%$, and $20.1 \%$ for the SCA of $9 \%, 18 \%$, and $26 \%$, respectively. When the SRA content was $2.4 \%$, the compressive strength of samples decreased with increasing SCA compared with reference S8. The decent degree was $6.3 \%, 11.3 \%$, and $16.8 \%$ for the SCA of $9 \%, 18 \%$, and $26 \%$, respectively, while the compressive strength of the sample with SCA and SRA is still over $90 \mathrm{MPa}$ after 28 days. The SCA was porous and concavo-convex, where the adhesive force between the aggregate and cement mortar in the interfacial transition area was greater than that of normal concrete.

The flexural strength decreased with an increase in the SCA content or the SRA content. And the flexural strength decreased with increasing W/B from 0.20 to 0.25 ; the flexural strength was almost constant with increasing W/B from 0.25 to 0.28 . Compared with reference $\mathrm{S} 1$, the flexural strength decreased $9.7 \%, 12.4 \%, 19.2 \%, 29.6 \%$, and $32.9 \%$, respectively, with increasing SCA from $9 \%$ to $44 \%$, the compressive strength decreased $1.9 \%, 7.5 \%$, and $13.7 \%$, respectively, with increasing SRA from $0.8 \%$ to $2.4 \%$, and the compressive strength decreased $2.9 \%, 12.4 \%$, and $34.2 \%$ as the $\mathrm{W} / \mathrm{B}$ increases from 0.20 to 0.25 . The pore structure and the 


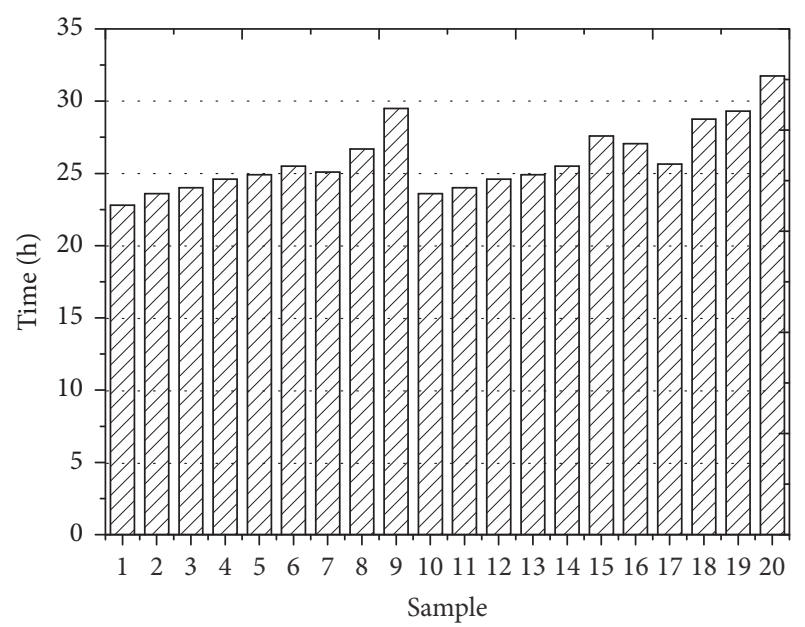

FIGURE 7: The initial setting time of pastes.

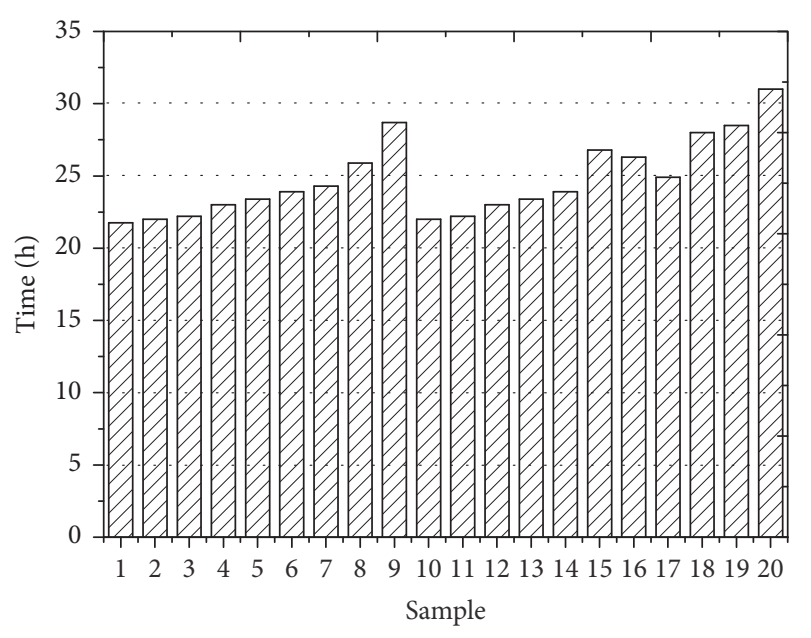

FIgURE 8: The final setting time of pastes.

homogeneity of UHPC were changed by the porous and brash SCA, the SRA, and more water, which damaged the fracture resistance of UHPC obviously, while flexural strength of the sample with SCA and SRA is still over $18 \mathrm{MPa}$ after 28 days.

3.2. Setting Time. The initial setting times of pastes are shown in Figure 7, and the final setting times of pastes are shown in Figure 8. In Figure 7, it is obvious that the initial setting time of UHPC paste in this research is above $20 \mathrm{~h}$. The initial setting time is much longer than the cement paste, which can be attributed to the high content of SF in the paste because of the poor hydration reactivity. The initial setting time occurred later with the SRA content increasing; the forepart hydration of cement could be delayed with the SRA. The initial setting time also occurred later with the total $\mathrm{W} / \mathrm{B}$ increasing. There is an induction period in the cement hydration, and the cement hydration would occur after the induction period. While there were many $\mathrm{Ca}^{2+}$ and $\mathrm{OH}^{-}$in the solution, the induction period was over after the $\mathrm{Ca}(\mathrm{OH})_{2}$ solution reached a certain saturation concentration and the

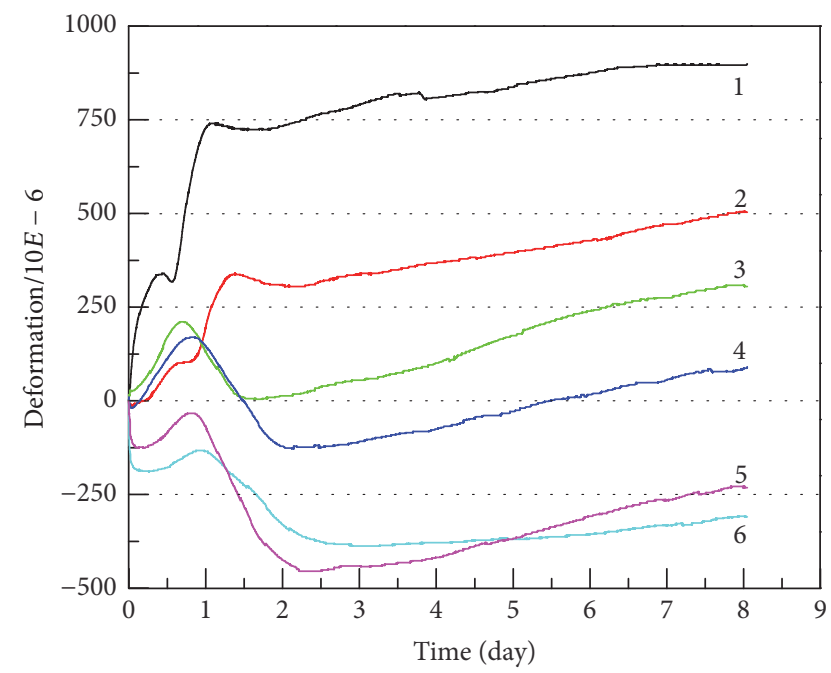

FIGURE 9: The autogenous shrinkage of references with SCA.

$\mathrm{Ca}(\mathrm{OH})_{2}$ crystals were produced. The $\mathrm{Ca}(\mathrm{OH})_{2}$ crystals were much harder to be produced when more water was in the cement, and the final time of induction period was much later and the initial setting time was much longer. It should be noticed that the initial setting time was delayed by the addition of SCA, because of the water in the SCA, while the initial setting time of pastes contained SCA that occurred slightly later than that of the pastes without SCA under the condition of same total W/B. The reason is that the initial setting time retardation occurs later than PC due to the fact that the water in the SCA is released slowly. Figure 8 indicates that the changed trend of the final setting time was similar to the initial setting time.

3.3. Autogenous Shrinkage. UHPC typically experiences significant autogenous shrinkage, because of the extremely low W/B and the high content of cement. The SCA and SRA were added to the pastes to mitigate the autogenous shrinkage. The experimental results, presented in the form of graphs, were obtained using the average measurements of three specimens.

3.3.1. SCA. Figure 9 visualizes the effect of the SCA in autogenous shrinkage. As is shown, the shrinkage rate increased strongly during the first day, the shrinkage rate of S1 and S2 was continuously on the increase during the second half of the first day, and the shrinkage rate of S3, S4, S5, and S6 decreased sharply one day later, while the shrinkage of all references presented stably after two days. It is noticed that the autogenous shrinkage deformation of S1 without SCA was $896 \mu \mathrm{m} / \mathrm{m}$, and the autogenous shrinkage of references decreased with SCA increasing. And the autogenous shrinkage of S6 was restrained; the SCA content of S6 was $44 \%$. The autogenous shrinkage is mitigated with the SCA mixing. This can be ascribed to that more water in SCA and the fine pore structure of SCA.

To judge whether either the water of SCA or the fine pore structure of SCA plays a greater role in decreasing the autogenous shrinkage, the autogenous shrinkage experiments of 
TABLE 4: The autogenous shrinkage deformation of references.

\begin{tabular}{lcc}
\hline Serial number & $\begin{array}{c}\text { The autogenous shrinkage of references } \\
\text { with SCA }\end{array}$ & $\begin{array}{c}\text { The autogenous shrinkage of references } \\
\text { with W/B }\end{array}$ \\
\hline 1 & 503 & 583 \\
2 & 305 & 556 \\
3 & 114 & 395 \\
4 & -232 & 308 \\
5 & -310 & 282 \\
\hline
\end{tabular}

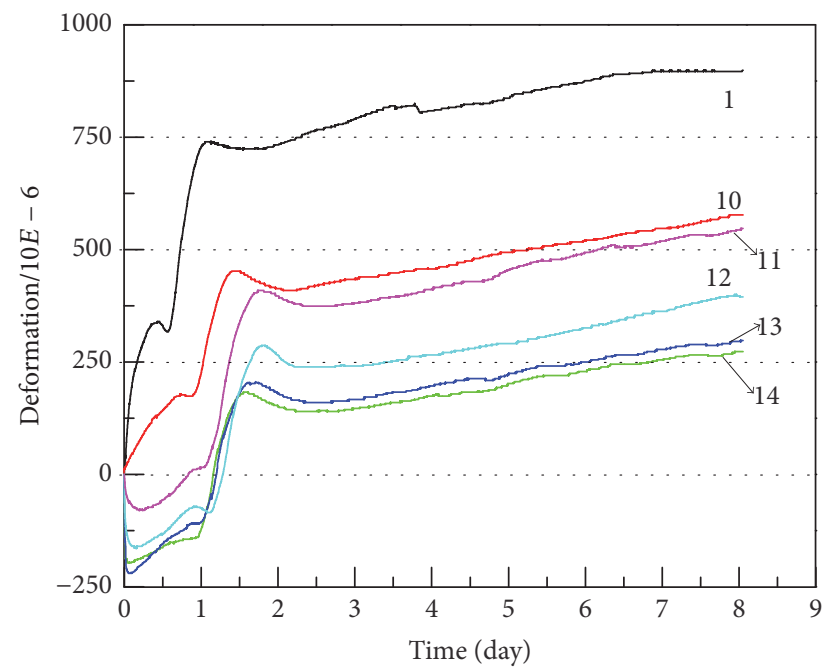

FIGURE 10: The autogenous shrinkage of references with different W/B.

reference samples with different $\mathrm{W} / \mathrm{B}$ were completed. The water content of reference samples with different $\mathrm{W} / \mathrm{B}$ is equal to the total content water of corresponding reference samples with SCA. Figure 10 visualizes the autogenous shrinkage of reference samples with different W/B. As shown in the figure, the autogenous shrinkage of references decreased with SCA increasing, This can be ascribed to that the capillary force increases with the denser matrix caused by lower W/B and as a result it will lead to higher self-desiccation and autogenous shrinkage. While the autogenous shrinkage was not restrained with the $\mathrm{W} / \mathrm{B}$ increasing, the lowest autogenous shrinkage deformation of references was $283 \mu \mathrm{m} / \mathrm{m}$.

The autogenous shrinkage deformations of references with SCA and corresponding W/B are shown in Table 4. It is noticed that the autogenous shrinkage deformation of references with SCA is lower than that with corresponding $\mathrm{W} / \mathrm{B}$. And, the difference between the autogenous shrinkage deformations of references with SCA and the autogenous shrinkage deformations of references with corresponding W/B increased with the SCA increasing. The internal curing with means of SCA is attributed to the autogenous shrinkage reduction, and the fine pore structure of SCA plays a decisive role for the autogenous shrinkage inhibition.

3.3.2. SRA. Figure 11 shows the autogenous shrinkage of reference samples with SRA. The results show that both

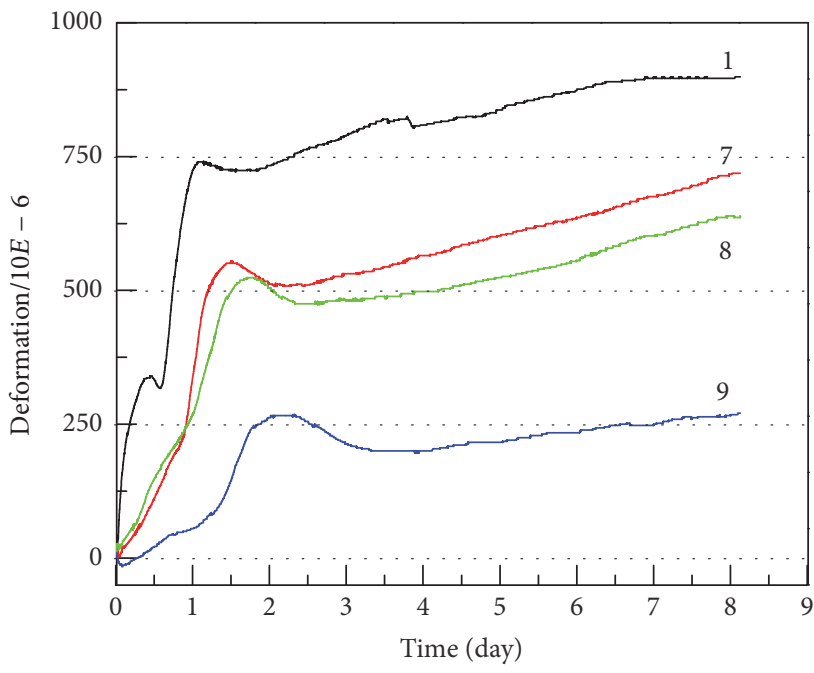

FIGURE 11: The autogenous shrinkage of references with SRA.

references with SRA mitigated the autogenous shrinkage and the autogenous shrinkage of references decreased with SRA increasing. The autogenous shrinkage deformation was 719,639 , and $285 \mu \mathrm{m} / \mathrm{m}$, respectively, with the content of SRA increasing $0.8 \%, 2.4 \%$, and $4 \%$. The reason of high efficiency with SRA adding is consistent with the higher ability of this SRA to reduce the surface tension of the interstitial solution, which could reduce the shrinkage caused by capillary tension [29]. The hardening of the paste and the formation of microstructure were slowed down in the early stage, which could mitigate the chemical shrinkage and autogenous shrinkage relatively, when the SRA was added to the paste. The addition of SRA was effective in mitigating the autogenous shrinkage, while the autogenous shrinkage of references with SRA was not restrained.

3.3.3. Mixture of SCA and SRA. The SCA and SRA were all added to the references to restrain the autogenous shrinkage. Figure 12 shows the autogenous shrinkage of reference samples with SRA or SRA-SCA, the SRA contents in S7, S15, S16, and S17 are all 0.8\%, and the SCA contents of S15, S16 and S17 are $9 \%, 18 \%$, and $26 \%$. It would be noted that the autogenous shrinkage deformation was reduced strongly with SRA-SCA adding, and the autogenous shrinkage decreased with SRASCA increasing. The addition of SCA was effective in reducing the autogenous shrinkage in the references with SRA; the autogenous shrinkage deformation was reduced $77.05 \%$ with 


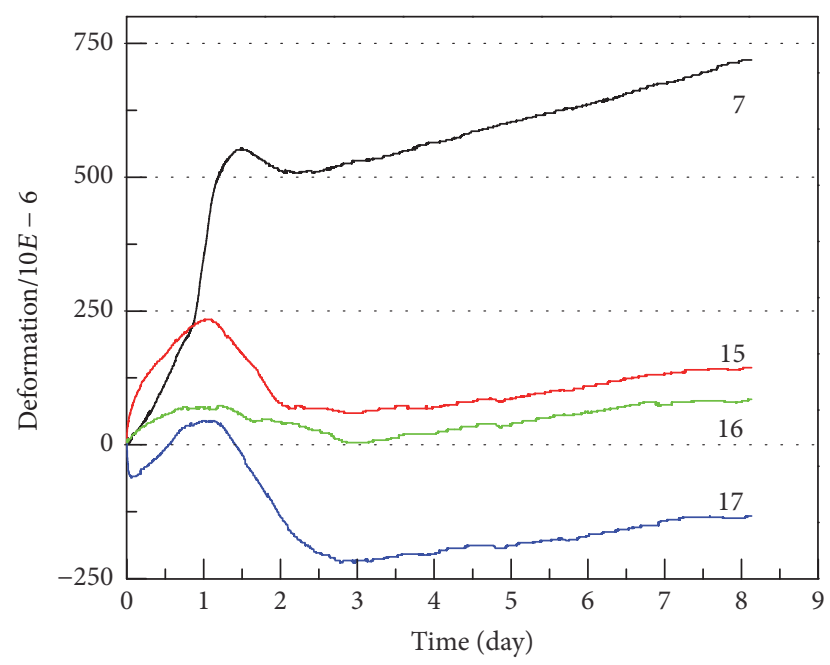

FIGURE 12: The autogenous shrinkage of references with SRA and SRA-SCA.

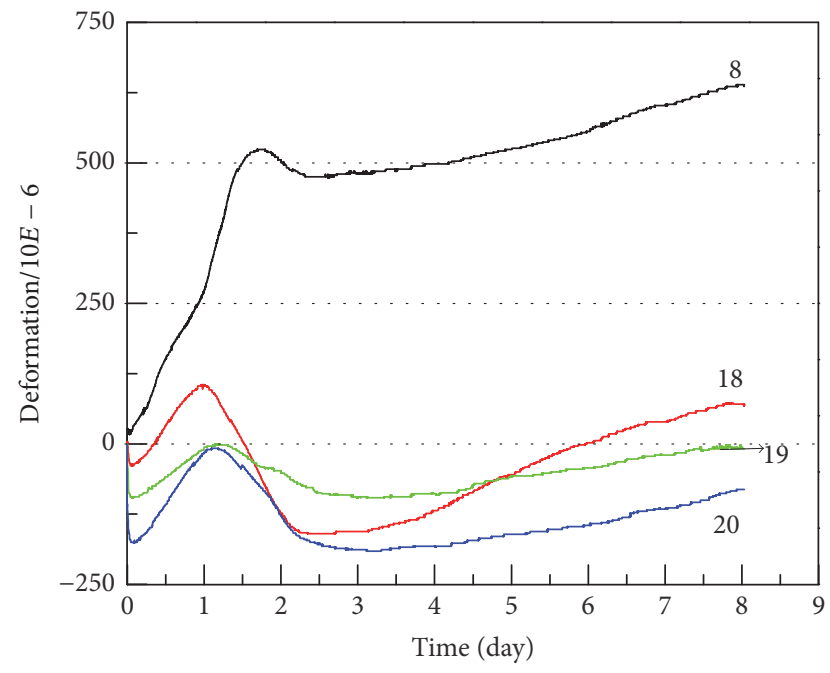

FIGURE 13: The autogenous shrinkage of references with SRA and SRA-SCA.

9\% SCA. And the autogenous shrinkage was restrained with $26 \%$ SCA. It appeared that SRA and SCA worked together to mitigate the autogenous shrinkage, enhancing the effect of each other in reducing shrinkage.

Figure 13 also visualizes the effect of the SRA and SRASCA in autogenous shrinkage, the SRA contents in S8, S18, S19, and S20 are all 2.4\%, and the SCA contents of S18, S19, and S20 are $9 \%, 18 \%$, and $26 \%$. The addition of SCA is seen to reduce the shrinkage deformation of the reference with SRA as seen from the figure. The autogenous shrinkage deformation was reduced $89.36 \%$ with $9 \%$ SCA, and the autogenous shrinkage was restrained with $18 \%$ SCA and $26 \%$ SCA.

In summary, the autogenous shrinkage of UHPC is mitigated effectively through the addition of SRA, SCA, and the mixture of SRA and SCA, and the autogenous shrinkage would be restrained at the suitable content. The reasons

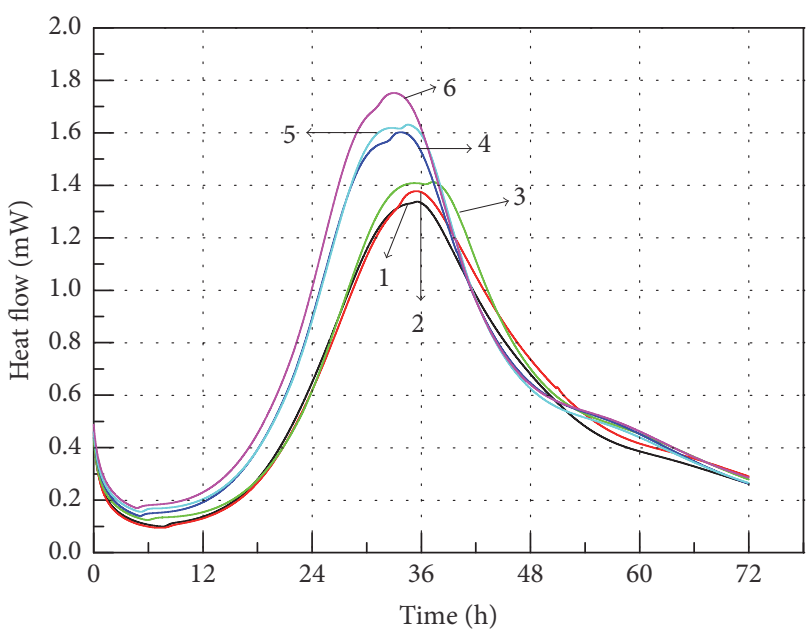

FIGURE 14: Heat flow versus time of references with SCA.

of that could be described as follows: the addition of SRA decreases the surface tension of the pore solution, thereby decreasing the Laplace pressure in the capillary pore solution, which could decrease the autogenous shrinkage of pastes. Additionally, the autogenous shrinkage is reduced through internal curing [30] with the use of SCA. What is more, the SRA and SCA will play an effective role together for the shrinkage reduction and will not counteract the effect of each other in decreasing the shrinkage.

3.4. Hydration of Pastes. The hydration heat flow of samples with SCA is presented in Figure 14. It is noted that the hydration heat flow decreased gradually during the first $7 \mathrm{~h}$, started to accelerate between $7 \mathrm{~h}$ and $10 \mathrm{~h}$, and peaked between $30 \mathrm{~h}$ and $36 \mathrm{~h}$. The time of the highest heat flow of UHPC was much longer than these ordinary pastes. The reason of that is the retardation of high content of superplasticizer, which was confirmed through the setting time test. As shown in figure, the main heat flow peak of references appeared early with SCA increasing, and the heat flow of references increased with SCA increasing. The water content of paste increased with SCA increasing, and the hydration reaction reacted rapidly and completely, which could be attributed to this phenomenon. Figure 15 shows the cumulative heat of the references with SCA and the cumulative heat increased with the SCA increasing as seen from the figure.

Figure 16 shows the heat flow of references with SRA. It is obvious that the induction and acceleration period of references became longer through adding the SRA. The heat flow peak of references appeared later with SRA increasing, and the heat flow of references decreased with SRA increasing. The arrival time of heat flow peak of S9 with 4\% SRA was about $12 \mathrm{~h}$ later compared to that of S1 without SRA. As seen in Figure 17, the cumulative heat of references also decreased obviously with SRA increasing. The reason of that is that SRA will delay the hydration reaction of cement.

The hydration heat flow of samples with SRA and SRASCA is presented in Figure 18. The SRA contents in S7, S15, S16, and S17 are all 0.8\%, and the SCA dosages of S15, S16, 


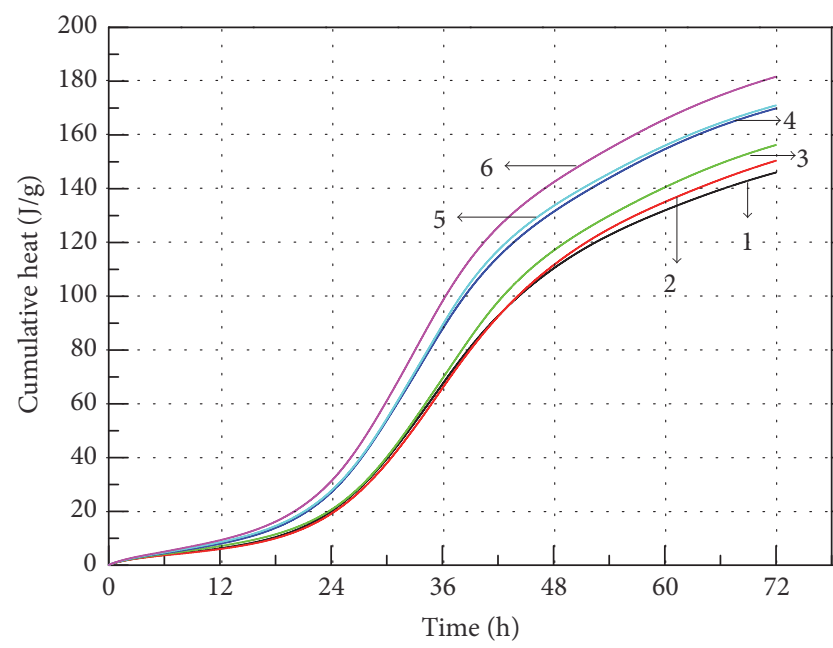

FIGURE 15: Cumulative heat versus time of references with SCA.

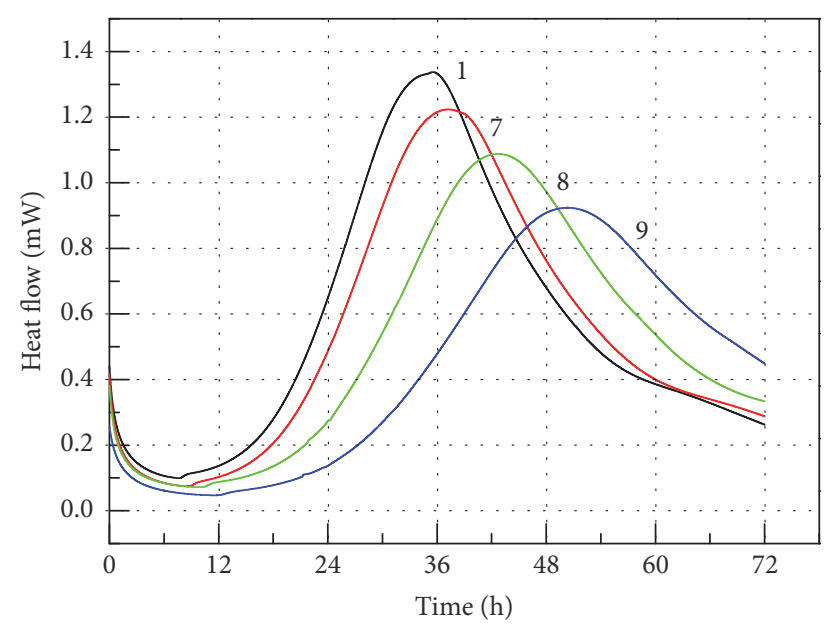

FIGURE 16: Heat flow versus time of references with SRA.

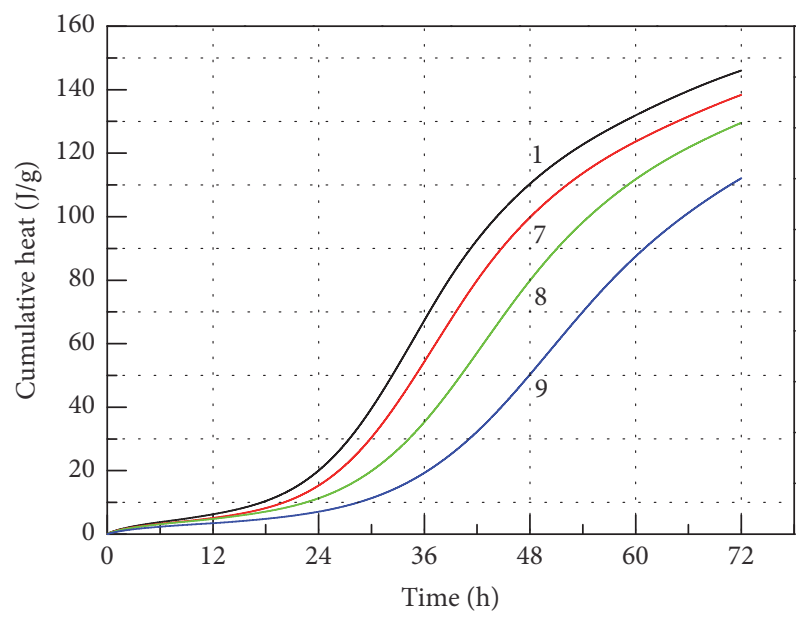

FIGURE 17: Cumulative heat versus time of references with SRA.

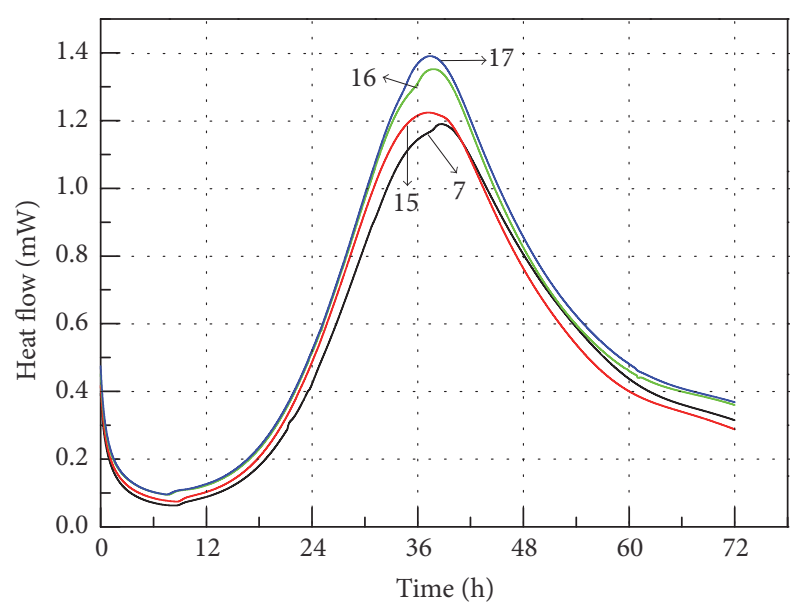

FIGURE 18: Heat flow versus time of references with SRA-SCA.

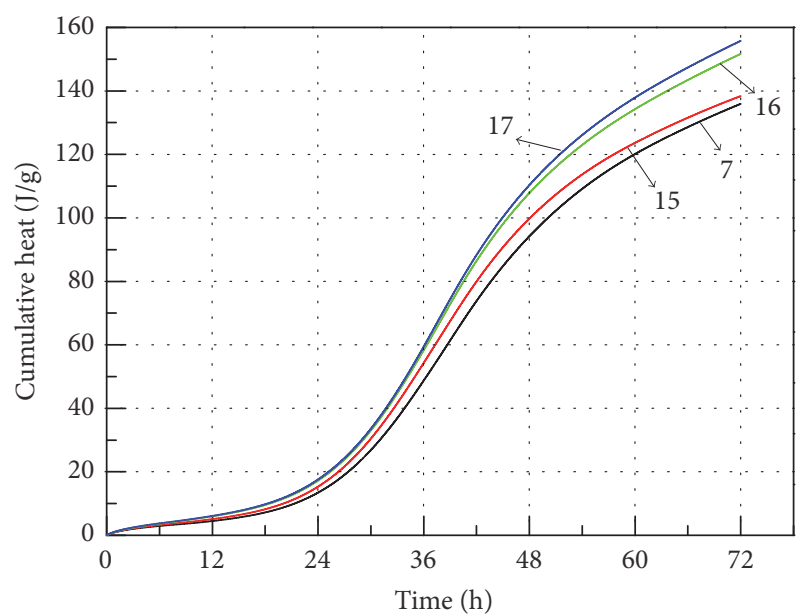

FIGURE 19: Cumulative heat versus time of references with SCASCA.

and S17 are $9 \%, 18 \%$, and $26 \%$. The arrival time of peak of references was nearly the same, while the heat flow of samples increased with SCA increasing because of more hydration reaction. The cumulative heat also increased with SCA increasing in Figure 19.

Figure 20 also visualizes the heat flow of samples with SRA and SRA-SCA. The SRA contents in S8, S18, S19, and S20 are all 2.4\%, and the SCA dosages of S18, S19, and S20 are $9 \%, 18 \%$, and $26 \%$. The experimental trajectories of S8, S18, and S19 were almost the same; the peak arrival time and the highest heat flow were nearly the same. The cumulative heat of S8, S18, and S19 followed the same pattern. The heat flow and the cumulative heat of S20 were higher than those of others. As shown in Figures 14-17, the addition of SRA delayed the arrival time of heat flow peak and reduced the cumulative heat, and the addition of SCA advanced the arrival time of heat flow peak and increased the cumulative heat, while these patterns were not obvious in Figures 18-21. The reasons of that were attributed to the fact that SRA and SCA counteracted the effect of each other in hydration 


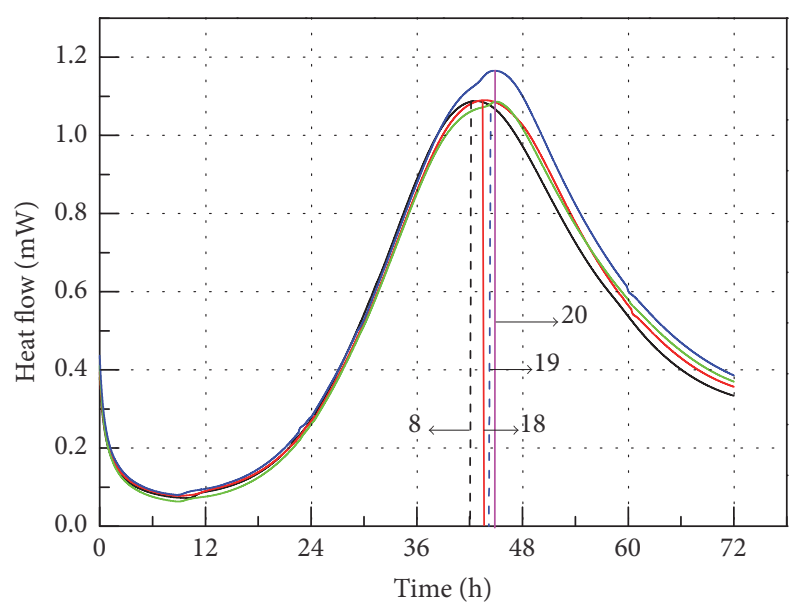

FIGURE 20: Heat flow versus time of references with SRA-SCA.

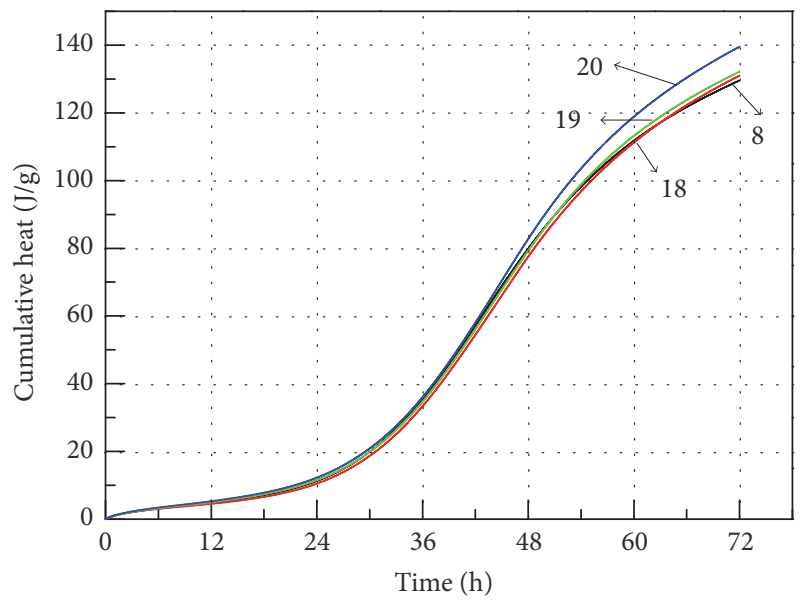

FIGURE 21: Cumulative heat versus time of references with SRASCA.

reaction, and the SRA played a more important role in hydration reaction than the water in SCA.

\section{Conclusions}

The effect of SCA, the effect of SRA, and the combined effect of SCA and SRA on the setting time, strength properties, autogenous shrinkage, and hydration of sample pastes were evaluated. The following conclusions are drawn from the results of this study:

(1) The addition of SCA into UHPC mitigated the autogenous shrinkage regardless of the dosage of SCA, while the use of SCA causes a less reduction in the compressive strength.

(2) The autogenous shrinkage of UHPC is decreased with the SRA adding, while the addition of SRA reduced the compressive strength and the flexural strength of pastes.

(3) Mixtures with SRA and SCA were the most effective in decreasing the autogenous shrinkage. The autogenous shrinkage restrained was observed in the mixture with $0.8 \%$ SRA and $26 \%$ SCA, the mixture with $2.4 \%$ SRA and $18 \%$ SCA, and the mixture with $2.4 \%$ SRA and $26 \%$ SCA. The SRA and SCA work together to decrease the autogenous shrinkage of UHPC and can strengthen the effect of each other in reducing shrinkage.

(4) The heat flow and cumulative heat of pastes are increased at the use of SCA, and the heat flow and cumulative heat of samples are decreased by the addition of SRA. The SRA plays much greater role in changing the heat flow and cumulative heat of pastes, when the SRA and SCA are all added to the pastes.

(5) The autogenous shrinkage of UHPC can be effectively mitigated through the internal curing by means of SCA, because of the fine pore structure in the coral sand.

\section{Conflicts of Interest}

The authors declare that they have no conflicts of interest.

\section{Acknowledgments}

The authors want to acknowledge Chongqing Basic Science and Frontier Technology Research Project (csct2017jcyjAX0263) and Chongqing Graduate Student Innovation Project (CYB17149) for the financial supports. The authors also want to acknowledge the Chinese National Science Foundation Project of CQ CSTC (cstc2015jcyjA30005 and cstc2014jcyjA50026). They want to thank Hanbing Xiao, who checked the English language of the paper.

\section{References}

[1] C. Shi, Z. Wu, J. Xiao, D. Wang, Z. Huang, and Z. Fang, "A review on ultra high performance concrete: Part I. Raw materials and mixture design," Construction and Building Materials, vol. 101, pp. 741-751, 2015.

[2] D. Wang, C. Shi, Z. Wu, J. Xiao, Z. Huang, and Z. Fang, "A review on ultra high performance concrete: Part II. Hydration, microstructure and properties," Construction and Building Materials, vol. 96, pp. 368-377, 2015.

[3] T. Deboodt, T. Fu, and J. H. Ideker, "Durability assessment of high-performance concrete with SRAs and FLWAs," Cement and Concrete Composites, vol. 57, pp. 94-101, 2015.

[4] D.-Y. Yoo, N. Banthia, and Y.-S. Yoon, "Effectiveness of shrinkage-reducing admixture in reducing autogenous shrinkage stress of ultra-high-performance fiber-reinforced concrete," Cement and Concrete Composites, vol. 64, pp. 27-36, 2015.

[5] D.-Y. Yoo, J. Kim, G. Zi, and Y.-S. Yoon, "Effect of shrinkagereducing admixture on biaxial flexural behavior of ultrahigh-performance fiber-reinforced concrete," Construction and Building Materials, vol. 89, pp. 67-75, 2015.

[6] E. Güneyisi, M. Gesoğlu, A. Mohamadameen, R. Alzeebaree, Z. Algın, and K. Mermerdaş, "Enhancement of shrinkage behavior of lightweight aggregate concretes by shrinkage reducing 
admixture and fiber reinforcement," Construction and Building Materials, vol. 54, pp. 91-98, 2014.

[7] M. José Oliveira, A. B. Ribeiro, and F. G. Branco, "Combined effect of expansive and shrinkage reducing admixtures to control autogenous shrinkage in self-compacting concrete," Construction and Building Materials, vol. 52, pp. 267-275, 2014.

[8] Y. Gu, Z. Wei, Q. Ran, X. Shu, K. Lv, and J. Liu, "Characterizing cement paste containing SRA modified nanoSiO $\mathrm{S}_{2}$ and evaluating its strength development and shrinkage behavior," Cement and Concrete Composites, vol. 75, pp. 30-37, 2016.

[9] T. Deboodt, T. Fu, and J. H. Ideker, "Evaluation of FLWA and SRAs on autogenous deformation and long-term drying shrinkage of high performance concrete," Construction and Building Materials, vol. 119, pp. 53-60, 2016.

[10] V. Mechtcherine and H. Reinhardt, "Effects of the combination of super absorbent polymers and shrinkage reducing admixtures on autogenous shrinkage of cement morta," Materials Review, vol. 138, pp. 151-161, 2016.

[11] S. Zhutovsky and K. Kovler, "Effect of internal curing on durability-related properties of high performance concrete," Cement and Concrete Research, vol. 42, no. 1, pp. 20-26, 2012.

[12] S. Afzal, K. Shahzada, M. Fahad, S. Saeed, and M. Ashraf, "Assessment of early-age autogenous shrinkage strains in concrete using bentonite clay as internal curing technique," Construction and Building Materials, vol. 66, pp. 403-409, 2014.

[13] W. Chen, J. Qian, B. He, J. Liu, L. Zhang, and X. Jia, "Effects of expansive agent and shale pottery on shrinkage reduction of lower water-cement ratio mortar," Kuei Suan Jen Hsueh Pao/Journal of the Chinese Ceramic Society, vol. 41, no. 4, pp. 505-510, 2013.

[14] S. Kawashima and S. P. Shah, "Early-age autogenous and drying shrinkage behavior of cellulose fiber-reinforced cementitious materials," Cement and Concrete Composites, vol. 33, no. 2, pp. 201-208, 2011.

[15] N. van Tuan, G. Ye, K. van Breugel, and O. Copuroglu, "Hydration and microstructure of ultra high performance concrete incorporating rice husk ash," Cement and Concrete Research, vol. 41, no. 11, pp. 1104-1111, 2011.

[16] M. Kaszynska and A. Zielinski, "Effect of lightweight aggregate on minimizing autogenous shrinkage in self-consolidating concrete," in Proceedings of the 7th Scientific-Technical Conference on Material Problems in Civil Engineering, MATBUD 2015, pp. 608-615, pol, June 2015.

[17] A. J. Klemm and K. S. Sikora, "The effect of Superabsorbent Polymers (SAP) on microstructure and mechanical properties of fly ash cementitious mortars," Construction and Building Materials, vol. 49, pp. 134-143, 2013.

[18] D. Saje, "Reduction of the early autogenous shrinkage of high strength concrete," Advances in Materials Science and Engineering, vol. 2015, Article ID 310641, 8 pages, 2015.

[19] M. Wyrzykowski, P. Trtik, B. Münch, J. Weiss, P. Vontobel, and P. Lura, "Plastic shrinkage of mortars with shrinkage reducing admixture and lightweight aggregates studied by neutron tomography," Cement and Concrete Research, vol. 73, pp. 238$245,2015$.

[20] D.-Y. Yoo, S.-T. Kang, J.-H. Lee, and Y.-S. Yoon, "Effect of shrinkage reducing admixture on tensile and flexural behaviors of UHPFRC considering fiber distribution characteristics," Cement and Concrete Research, vol. 54, pp. 180-190, 2013.

[21] M. Gesoglu, E. Güneyisi, H. Ö. Öz, M. T. Yasemin, and I. Taha, "Durability and Shrinkage Characteristics of Self-Compacting
Concretes Containing Recycled Coarse and/or Fine Aggregates," Advances in Materials Science and Engineering, vol. 2015, Article ID 278296, 2015.

[22] Ministry of housing and urban rural development of People's Republic of China, Concrete structure engineering construction standard:GB 50666-2011, China Building Industry Press, China, 2014.

[23] Ministry of Construction of the People's Republic of China, Reactive Powder Concrete: GB/T 31387-2015, China Building Industry Press, China, 2016.

[24] Ministry of Construction of the People's Republic of China, Ordinary Concrete Mechanics Performance Test Method: GB/T 50081-2002, China Building Industry Press, China, 2003.

[25] C. Jiang, Y. Yang, Y. Wang, Y. Zhou, and C. Ma, "Autogenous shrinkage of high performance concrete containing mineral admixtures under different curing temperatures," Construction and Building Materials, vol. 61, pp. 260-269, 2014.

[26] D. Shen, X. Wang, D. Cheng, J. Zhang, and G. Jiang, "Effect of internal curing with super absorbent polymers on autogenous shrinkage of concrete at early age," Construction and Building Materials, vol. 106, pp. 512-522, 2016.

[27] C. H. Lee, K. C. Hover, and A. Lee, "The effects of sieving and paste content on the Setting behavior of mortars as measured by ASTM C403," Journal of Testing and Evaluation, vol. 43, no. 6, pp. 1350-1360, 2015.

[28] B. Kucharczyková, L. Topolář, P. Daněk, D. Kocáb, and P. Misák, "Comprehensive testing techniques for the measurement of shrinkage and structural changes of fine-grained cement-based composites during ageing," Advances in Materials Science and Engineering, vol. 3, pp. 91-98, 2014.

[29] M. S. Meddah, M. Suzuki, and R. Sato, "Influence of a combination of expansive and shrinkage-reducing admixture on autogenous deformation and self-stress of silica fume highperformance concrete," Construction and Building Materials, vol. 25, no. 1, pp. 239-250, 2011.

[30] S. Zhao, C. Li, M. Zhao, and X. Zhang, "Experimental Study on Autogenous and Drying Shrinkage of Steel Fiber Reinforced Lightweight-Aggregate Concrete," Advances in Materials Science and Engineering, vol. 2016, Article ID 2589383, 2016. 

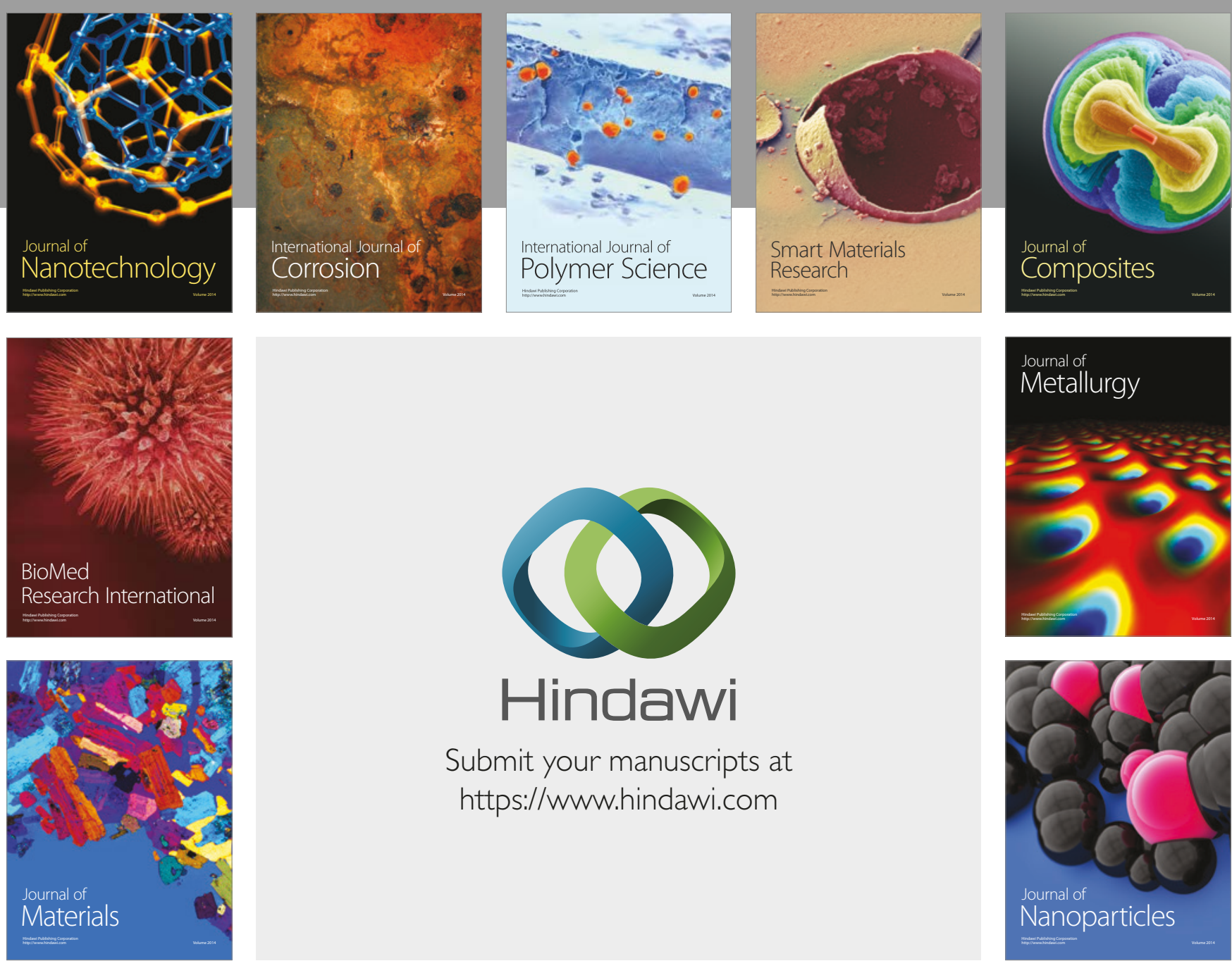

\section{Hindawi}

Submit your manuscripts at

https://www.hindawi.com
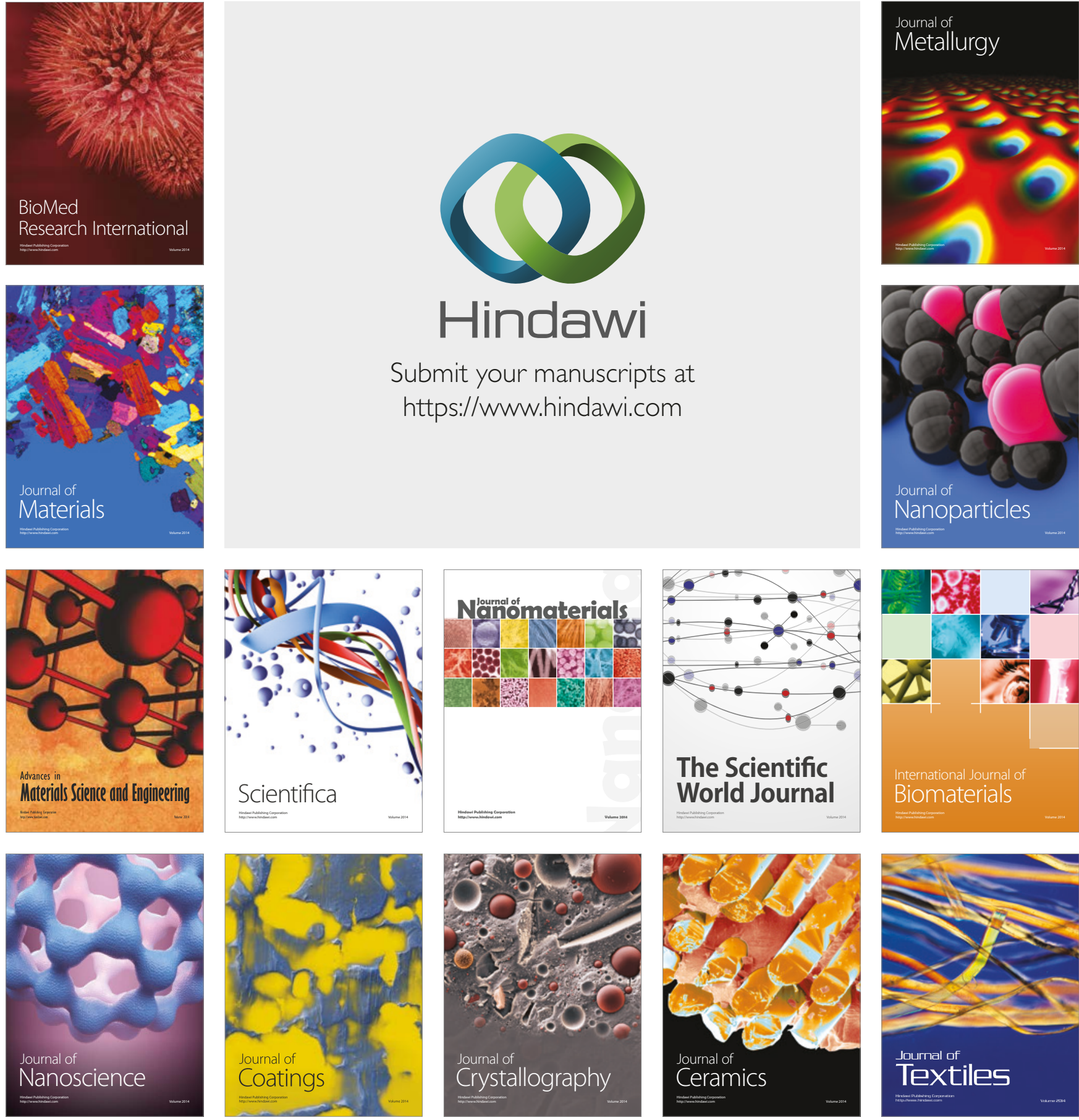

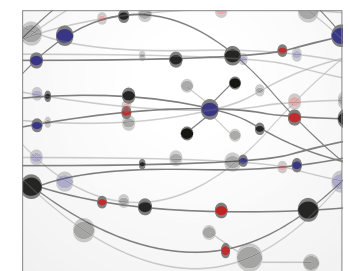

The Scientific World Journal
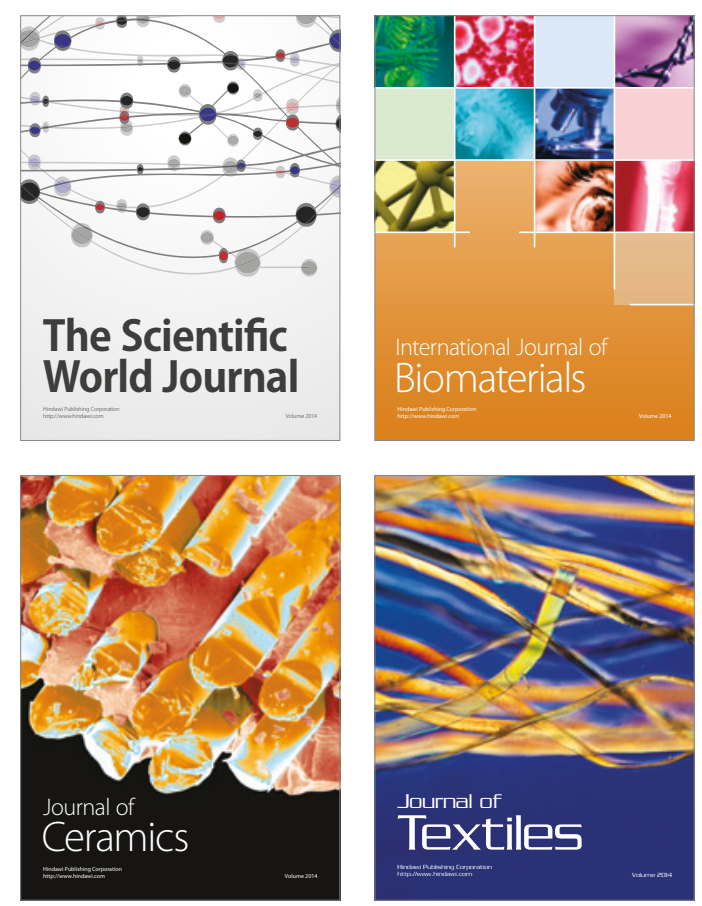